\title{
Study of University Students' Foreign Language Speech Activity Formation
}

\author{
Agzam A. Valeev ${ }^{1}$, Lilia A. Valeeva ${ }^{1} \&$ Albina F. Sirazeeva ${ }^{1}$ \\ ${ }^{1}$ Kazan (Volga region) Federal University, Kazan, Russia \\ Correspondence: Agzam A. Valeev, Kazan Federal University, Kremlyovskaya Street 18, Kazan, 420008, Russia. \\ E-mail: valeykin@yandex.ru
}

Received: January 19, 2014

Accepted: February 22, 2015 Online Published: March 25, 2015

doi:10.5539/res.v7n5p38

URL: http://dx.doi.org/10.5539/res.v7n5p38

\begin{abstract}
Today the scope of international activity of Russia has increased. In this regard, there has appeared a steady demand for a good knowledge of one of the European languages (English, French or German). However, in teaching university students there is still a number of problems: poor development of pedagogical conditions for increasing the efficiency of university students' foreign language speech activity; the problem of the evaluation criteria of speech development level and technological organization of students' language development; ignorance of its methodological and linguodidactic foundations; uncoordinated study of foreign and native languages; lack of consideration of the motivational features of student's linguistic personality formation, etc. The article reveals the essence, structure and content of foreign language speech activity. The use of problem-solving communication speech and grammar exercises ensures the successful formation of foreign language speech activity in the learning process that forms a meaningful basis for speech activity. The article determines the principles of its organization and presents a structural and functional model of the development of foreign language speech activity. The results of experimental work suggest the viability of structural and functional model of university students' speech activity formation. The model shows a correlation of its components, justifies pedagogical conditions for its effective implementation, reveals students' speech activity development level, provides the criteria, proposes diagnostic tools, as well as the complex of problem-solving and communication methods for the future formation of the main types of students' speech activity that provide professional character and meaningful basis for foreign language speech activity.
\end{abstract}

Keywords: linguistic identity, foreign language speech activity, speech development, verbal skills, speech functionality, communication methods, professional character of learning process, situation of speech communication, communication needs, university students

\section{Introduction}

\subsection{Actualization of the Problem}

Nowadays there are a number of trends in the process of intensification of teaching university students. They include the integration of professional and general cultural training of specialists alongside with the development of their personal qualities; striving for self-realization and creative self-expression; the transition to modular curriculum development with a wide range of elective courses; adoption of rating system for students' knowledge assessment; a great number of opportunities for self-study; introduction of open systems of intensive training in educational process, etc (Levina et al., 2015; Shaidullina et al., 2014, 2015; Kalimullin, 2014; Masalimova et al., 2014; Sibgatova et al., 2015). Concerning the formation of the linguistic identity of a new multi-lingual type, today there is a search for the means to ensure the effectiveness of university students' foreign language speech activity, which affects the fundamental structure of didactics, pedagogical psychology, cultural studies (in particular, the ethnic culture). However, pedagogical conditions to increase the efficiency of university students' foreign language teaching haven't yet been studied enough so far. That leads to a contradiction with the needs of social, national (ethnic and cultural) and pedagogical practice. There is a certain difference between the importance to increase the general cultural level of the young generation, their speech culture and its low current level, and the lack of methodological and scientific support of this process. In this regard, there arises a necessity for theoretical understanding of accumulated changes in teaching practice and their reflection in the objectives, content, technology, formation of foreign language speech activity. 


\subsection{Explore Importance of the Problem}

Pedagogical understanding of the problem of university students' foreign language speech activity is connected with the formation of student's self-concept and civic education (Valeeva, Koroleva, \& Sakhapova, 2014; Gutman et al., 2014; Lopatina et al., 2015). In foreign language teaching there is the notion of "foreign language classroom speech activity." At present, this term is used to differentiate intrinsic speech activity, i.e. activity in the process of real communication, from the one that is modeled specifically for educational purposes and takes place during the foreign language classes. Its two-part character is presented in the fact that in the process of foreign language activity speech techniques as well as learning activity techniques are formed. It would even be better to say that through learning activity techniques speech activity in a foreign language is formed.

The study defined understanding of the phenomenology of university students' foreign language classroom speech activity. It is a system of training and speech exercises, which have a certain structure, perform different functions and are meaningful and effective. Formation of foreign language speech activity involves a special organization of the process as an integrated consistent system. In learning a foreign language the mastery of specific actions involves not only the study of grammar, vocabulary, phonetics and stylistic features, but also a focus on the culture and history of the country the language is spoken, which is due to an indisputable fact of dialectical unity of language and culture (Shakirova \& Valeeva, 2014; Lopatina et al., 2015). Without certain minimum knowledge of the country the act of human communication cannot be completed. In the development of university students' foreign language speech activity it is increasingly important to encourage, use and develop communication needs of learners related to social need and individual interest in the target language.

\subsection{Pedagogical Conditions for Increasing Efficiency of University Students' Foreign Language Speech Activity}

To improve the quality of teaching a foreign language it is necessary to provide the following pedagogical conditions:

- Modeling situations of speech communication (teaching communication in a language implying a holistic view and study of the situation as a multidimensional structure, all levels and components of which present an integrated system);

- Consideration of bilingualism and multilingualism laws (the use of linguistic experience of students both in the field of language and speech skills);

- Consideration of communication needs of learners (setting aggregate communication needs of students for communicative type of training);

- Compliance of the language material with the task of teaching a particular type of speech activity (matching the scope and structure of foreign language curriculum, intended for a particular type of learners, with the variety of literary language, its forms and at the same time - the type of speech activity).

\subsection{Status of a Problem}

Analysis of the theory and practice of education in this field demonstrates the lack of research of the problem of pedagogical conditions for increasing the efficiency of university students' foreign language speech activity by means of a foreign language. The problem of improving the teaching of foreign languages is analyzed in the works of the psychologist Vygotsky (1983), the linguist Leontiev (1969), who viewed language teaching as the formation of speech activity. The conceptual bases of the research of foreign language speech activity formation problem are considered in the works of Zimnyaya (1991), Rakhmanov (1980). Significant contribution to the development of theory and methods of intensification of a foreign language teaching was made by Gegechkori (1978), Kitaygorodskaya (1986), Lozanov (1979), Passov (2000), Plesnevich (1977) and Petrusinsky (1987). The problem of increasing the effectiveness of bilingual education was studied by Gabdulhakov (2014), Harisov (1998), Galishnikova (2012), Valeev (2013), Sabirova (2013) and Baklashova (2014). Great contribution to the study of psychological and linguistic characteristics that determine the formation of foreign language speech activity of students was made Belyaev (1965), Bim (1997), Gez (1974), Passov (2000), Shcherba (1974), Oller (2014), Stevick (1990), Shrum and Glisan (2004) and Rivers (1968). Belyaev (1965) proposed the definition of foreign language speech activity as the process of communication, such as foreign language speech practice and training. Bim (1997), Zimnyaya (1991) and Shcherba (1974) in their works give the analysis of the functioning of speech automatisms in the 4 language skills: speaking, listening, reading and writing. This analysis shows that most leading psychologists and linguists view speech as an activity. A thorough study of the structure of the linguistic identity was held by the researcher Karaulov (1987). Austin (1986) worked out in detail the structure of the speech act. The analysis of the works of the abovementioned authors and many other publications in this field showed that the issues related to the research of forming a linguistic identity is still an understudied area of scientific 
knowledge.

\subsection{Hypothesis of the Research}

Analysis of theoretical studies and practical activities in the aspect of the problem studied showed that the formation of university students' foreign language classroom speech activity will proceed successfully providing that:

- Training will be organized on the basis of the principles of student-centered teaching; authenticity associated with the consideration of cultural values and broadening students' linguistic and geographic horizons; professionoriented training, multilingualism; cognitive oral communication activity, functionality;

- Training model structure will include components activating students' creative autonomy;

- There will be used the complex of problem-solving communication methods of forming the 4 language skills ensuring professional orientation and meaningful basis for classroom speech activity;

- Tutors will apply the developed model of educational technology of students' classroom speech activity formation as an integrated set of didactic, psychological and methodological procedures.

\section{Materials and Methods}

\subsection{The Tasks of the Research}

In the course of the study the following tasks were set: 1) on the basis of scientific analysis of philosophical, psychological and pedagogical, linguodidactic literature to reveal the essence of classroom speech activity and to determine the principles of its organization; 2) to carry out a methodological and substantive analysis of the concept "educational technology"; 3) to develop a theoretical model of technology of university students' foreign language classroom speech activity formation and experimentally demonstrate its effectiveness; 4) to develop a set of problem-solving and communication methods of forming university students' 4 language skills that provide professional orientation and informative basis for classroom speech activity.

\subsection{Theoretical and Empirical Methods.}

To test the hypothesis there was implemented a complex variety of methods, complementing each other:

- Theoretical-Analysis of psychological and pedagogical literature on research; study and generalization of innovative teaching experience;

- Empirical—Participant observation, stating and forming pedagogical experiment, survey, testing, interviews, discussions, study of the results of students' academic and extracurricular activities, statistical treatment of data; interpretation and evaluation of the results of experimental work.

\subsection{The Trial Infrastructure and Stages of the Research}

The trial infrastructure for the study was provided by the Institute of Language and the Institute of Management, Economics and Finance of Kazan (Volga Region) Federal University. The study was conducted in three stages.

At the first stage (2009-2010) there was examined the state of the problem in the scientific literature and teaching practice and developed the initial basis of the study: the empirical material was gathered, students' relationships were studied, the causes of the problems in communication in the educational and socio-cultural spheres of life were identified, techniques of formation of cognitive oral communication activity, that are part of the content of classroom speech activity, were settled and developed.

At the second stage (2011-2012) there was conducted a research on best practices of universities, and a number of teachers, as well as the preliminary hypothesis of the study was formulated: the model and program of implementing the educational technology of students' classroom speech activity formation were developed; surveys and interviews with students and teachers were conducted; interpretation of students' test-papers was made, quantitative and qualitative analyses of pedagogical phenomena via the methods of mathematical statistics were conducted.

At the third stage (2013-2014) there was carried out experimental verification of educational technology of university students' classroom speech activity formation and the effectiveness of its implementation.

\subsection{Evaluation Criteria}

Evaluation of the effectiveness of students' foreign language speech activity formation was carried on the basis of the following criteria:

- Focus on the information (selection of core sentences on the basis of structural elements of a microtext: setting, 
the main part and resolution);

- Logical coherence of speech (consideration of a strong logical chain, where sentences are irreversible; a weak logical chain, where you can change the sequence of sentences; lack of logical and linguistic connection, i.e. the combination in adjacent sentences of non-correlating concepts);

- Conceptual (keeping the total number of words in a sentence, the total number of concepts, well-known concepts, specific concepts derived from common usage, little-known specific concepts of foreign origin) and syntactic complexity of sentences.

\subsection{Experimental Procedure and Its Description}

The main objective of the study was to prove that educational technology which was developed on the basis of hypotheses and conceptual foundation helps improve students' foreign language classroom speech activity, ensuring the formation of speech skills and communicative competence.

The experiment consisted of three parts: stating, researching and forming. The stating experiment was done in three years (2009-2010) in three phases. The first phase of the experiment included the survey of English classes with the aim to analyze cognitive oral communication activity of students in the learning process. Diagnosis and analysis were carried out using a set of methods: questionnaires, observations, interviews with students and teachers, checking of paper tests, the analysis of students' progress.

The second phase was to identify the level of formation of speech and language skills and communicative competence through linguodidactic testing, which was presented by our system of language and speech tests with the variability of the form and content of tasks aimed at diagnosis of foreign language speech activity of students in speaking, reading, listening and writing.

The third phase involved the observation of students' foreign language communication activities during tests and examinations in English.

The results of stating experiment showed a small number of students who have attained high and medium level of foreign language communication skills' development in the learning process according to traditional methods. In the process of stating stage of the experiment the model of educational technology was tested, that was aimed at training and formation of classroom speech activity of university students, where important structural components were the criteria and levels of language skills' development.

On the basis of efficiency criteria of students' foreign language speech activity the levels of its formation were identified: low, medium and high.

Formative experiment was carried out in three phases during 2013-2014 period: the first phase was aimed at the formation of active and reflective motives of students' autonomous speech activity; the second step was the formation of 4 language skills (speaking, reading, listening and writing); the third phase involved the use of communication skills and communicative competence in the process of autonomous speech activity under conditions of spontaneous communication.

\section{Results}

\subsection{Methods of Grammar Skills Formation in Speaking as One of the Four Skills Activities}

Purpose, principles, content, psycholinguistic peculiarities of foreign language speech activity allowed to summarize and offer the following forms, methods, techniques and means of forming this type of activity in university students' learning:

- Group of traditional methods: verbal, visual, practical (different types of training; reproductive exercises "virtual tests"; question-answer form of work, etc.);

- Group of problem-solving and creative methods (acting out plays; writing essays on any subject; using the project method; brainstorming);

- Methods of intensive training (role, language and dramatic playing; discussion; playing sketches of the finished story; "chain"; "transaction");

- Research methods (independent study; comparison of various linguistic phenomena). While using these methods, we observed the dynamics of the gradual transition from mechanical algorithmic methods to heuristic ones.

As a result, there have been identified the following skills, the development of which is a condition for communication skills' formation: 
- To pronounce the phrases causing difficulties correctly;

- To divide sentences into syntagmas, to form each syntagma intonationally;

- To put logical sentence stress;

- To choose intonation model of sentence according to communicative task;

- To use the following according to the situation of speech communication and communicative task: conjunctions/linking words in the subordinate clause of condition, time, cause and concession; conjunctions/linking words to link the individual sentences in an utterance; associative model ("reversible" and "irreversible"); prepositions in phrases; speech formulas of different groups (to express modality, evaluation, filling in pauses etc.);

- To structure sentences of different types of communication and to combine them in one utterance according to the situation of speech communication and communicative task;

- To understand the significance of polysemantic lexical units in different contexts;

- To determine the semantic center of the phrase according to intonation;

- To divide the sentences (to identify aurally the border of phrases in a sentence) in a partner's utterance;

- To identify the sentences included into the detailed utterance of a partner, in accordance with intonation patterns;

- To identify and understand the logical, temporal, cause-and-effect relations between the parts of the sentences and utterances within the partners' phrases based on conjunctions, linking words, and by means of inter-phrase connection.

\subsection{Solution of Primary Tasks of Didactics}

Stating the problem of students' foreign language speech activity formation in the framework of "Foreign Language" discipline we took into account the specifics and scope of cultural information; interdisciplinary nature of a foreign language in the general system of the humanities; professional orientation of foreign language teaching at university; features of intercultural communication in a multi-language educational space; the specifics of the English language as a means of international communication. In this regard, in the course of the experiment the following tasks were accomplished: to achieve the so-called "100 per cent" of communication or fluency in a foreign language within the time period. Conducted pilot training revealed the influence of the established system of methodological tools to enhance oral-speech activity of students and the formation of their functionally-oriented, contextually specified, variability and correct speech during the work on the home and professional-oriented themes.

Assessment of students' oral communication skills and abilities was made by way of focusing on the following in their speech: the ability to socialize in public, to keep up and complete the conversation; verbal means of communication appropriate to the situation; the availability of certain lexical and grammatical synonyms; lack of linguistic errors. In this regard, in the course of training teachers need to help students to arrange thoughts, to bring clarity to the solution of the communication problem, to define the search of means for its solution, to create the conditions for natural communication in the target language, when that language is not an end in itself, but a means of communication.

\subsection{The Procedure and Results of the Experiment}

To carry out the experimental work there were formed three sub-groups of Kazan Federal University students with the aim of testing the effectiveness of the technology on the formation of students' foreign-language speech activity.

During the experiment, analyzes and generalization of observations and measurements of intermediate levels of the main parameters of speech activities' results carried out in order to clarify the formative stage of pedagogical experiment. This allowed us to make adjustments in the course of experimental work to determine the prospects for improving the process of formation of students' foreign language speech activity.

In the course of experimental work validation of the hypothesis of the study was carried out. The use of special topics allowed to determine another object of control-speech proficiency, measured by the ability to draw conclusions and to structure evidence and description with the means of the target sublanguage.

During the pilot training there were conducted four current and final assessment tests. Supervision was carried out in oral and in written forms. 
The registration data of assessment tests were analyzed by statistic processing. The obtained results showed the growth of indicators in all groups of selected speech formation parameters.

Comparison of the experimental work's final results led to the tendency of growth of speech parameters controlling indicators, during longer training period in the proposed method.

Diagnosis of significant characteristics of students' foreign speech based on criteria of information concentration, logical coherence of speech, syntactic and conceptual complexity of the statements made by the students also demonstrated the effectiveness of our technology of students' foreign language speech activity formation. The results of analysis are presented in table 1 .

Table 1. Results of Kazan Federal University students' foreign language speech activity analysis

Basic parameters of speech activity Control group $\quad$ Experimental group

(in \%) (in \%)

\begin{tabular}{|c|c|c|}
\hline $\begin{array}{l}\text { 1. Sufficient level of information concentration. The correctness } \\
\text { of the structure of a complex syntactic unit }\end{array}$ & 28 & 63 \\
\hline 2. The syntactic complexity of utterances & 41 & 56 \\
\hline 3. Level of conceptual complexity of statements & 23 & 42 \\
\hline 4. Logical interconnection of sentences in statements & 34 & 59 \\
\hline
\end{tabular}

Diagnosis of Kazan Federal University students' speech activity, we conducted in different years (2010, 2012, 2014) and in different conditions, confirmed the validity of chosen pedagogical ways of implementing effective English learning technology.

Formation of speech activities that are a part of foreign language speech activity of university students made us to have fundamentally new learning process organization, the implementation of which was possible with the following principles: the principle of student-centered learning (human experience formation of personal self-organization, which is expressed in constant readiness to perform specific personality functions in relation to the world around and their own life activity); the principle of authenticity (associated with the criterion of cultural values broadening students' linguistic and geographic horizons); the principle of profession-oriented training (formation of individual determination, including awareness of objectives and interest to the profession, the propensity to be engaged in some form of activity and emotional attitude towards it); the principle of multilingualism (the formation of the individual skills and abilities, allowing to use different languages both in oral and written forms depending on the situation and gain understanding in the communication process); the principle of cognitive oral communication activity (motivation and the use of communicative needs of learners, their development, associated with the public needs and individual interest in a target language); the principle of functionality (reliance on system of speech means, functioning in the process of communication (word collocations, phrases, super-phrasal unity), which are combined in a problem situation and socio-cultural context).

The article discloses the purposes, the content and organization of a foreign language learning system in the formation of students' foreign language speech activity and highlights its communicative component, which is reflected in a particular technological scheme of this type of activity formation, including the following components:

target (the formation of the linguistic identity); content (integration of content with the content of subjects in university; integration of the national culture and language with the contents of linguistic material; gradual complication of learning content; diagnosis of language proficiency and personal development);

principles (the principle of student-centered learning, the principle of authenticity associated with the criterion of cultural values broadening students' linguistic and geographic horizons, the principle of profession-oriented training, the principle of multilingualism, the principle cognitive oral communication activity, the principle of functionality);methods (traditional methods, problem-solving and creative methods and the methods of intensive training, the research methods); forms of class organization (individual work, pair work, work in minigroups, groups, whole class work); means of implementation (a combination of reproductive, reproductive and creative 
and creative activities; individual research work of students) and the criteria of foreign language speech activity formation (data concentration, logical coherence of speech, conceptual and syntactic complexity).

\section{Discussions}

The basic premise, which contributed to university students' foreign language speech activity formation, is the increasing role of foreign language and its influence on the spiritual and intellectual development of young people. As an alleged final result of foreign language speech activity, as well as any other activity, serves the transformed reality which is associated, however, with cognitive and practical needs of students. The end result, or product of a foreign language speech activity is knowledge acquired, skills, mastering the ways for their accumulation, which act as a framework for the future learning and contribute to the development of the young person. Products of foreign language speech activity reflect not only the objectivity, but also spirituality, social and personal relationships. Objectivity and spirituality as components of the content of foreign language communication have different sources, but move towards each other. Their intercross creates productive speech activity; if not, the real foreign language communication will not take place, but will be supplemented by the reaction.

\section{Conclusion}

Thus, we developed a technology model of university students' foreign language speech activity formation based on general and specific characteristics of psychological and pedagogical science: procedurality, project planning, use of effective methods of learning as well as algorithms and patterns, high performance, manageability, cost-efficiency, optimality, reproducibility and revision.

\section{Acknowledgments}

The work is performed according to the Russian Government Program of Competitive Growth of Kazan Federal University

\section{References}

Austin, J. L. (1986). Word as an action: The new in foreign linguistics (p. 17). Moscow: Progress.

Baklashova, T. A. (2014). Manager's Professional Training in Russia: Syllabus and Technologies. Procedia - Social and Behavioral Sciences. ERPA International Congress on Education, 152(7), 1057-1061. http://dx.doi.org/10.1016/j.sbspro.2014.09.274

Belyaev, B. V. (1965). Essays on the psychology of teaching foreign languages. Moscow: Prosvescheniye.

Bim, I. L. (1997). Methodology of teaching foreign languages as a science and the problems of school textbook. Moscow: Nauka.

Bodalev, A. A. (1983). Personality and communication. Moscow: Pedagogika.

Gabdulkhakov, V. F. (2014). The Problems of Language Personality Formation in Russia (the Analysis of Language Processes and Pedagogical Technologies). Procedia-Social and Behavioral Sciences. Third Annual International Conference "Early Childhood Care and Education", 146, 158-162. http://dx.doi.org/10.1016/j.sbspro.2014.08.104

Galishnikova, E. M. (2012). The conceptual keystones of training specialists in the system of additional professional education. Modern research of social problems (electronic scientific journal), 4(12). Retrieved from http://www.sisp.nkras.ru

Gegechkori, L. S. (1978). Basic methods of adult speech intensive training in a foreign language (Ph.D. dissertation). Moscow.

Gez, N. I. (1974). Oral communication: Essays on teaching the German language (pp. 50-97). Moscow: Vysshaya shkola.

Gutman, Y. Y., Masalimova, A. R., Shaidullina, A. R., Nizamieva, A. M., \& Myhamadieva, A. H. (2014). Foreign Language discipline integrative potential in the students' research competence forming. American Journal of Applied Sciences, 11(7), 1099-1103. http://dx.doi.org/10.3844/ajassp.2014.1099.1103

Kalimullin, A. M. (2014). Improvement of teachers' qualification at Kazan federal university. World Applied Sciences Journal, 30(4), 447.

Karaulov, Y. N. (1987). The Russian language and linguistic identity. Moscow: Nauka.

Kharisov, F. F. (1998). Language and nation: Environmental problems in terms of multilingualism. Kazan: Shkola. 
Kitaygorodskaya, G. A. (1986). Methodological foundations of intensive foreign language training. Moscow: MSU

Lapidus, B. A. (1986). The problem of the content of language teaching in university. Moscow: Vysshaya shkola.

Leontiev, A. A. (1969). Language, speech, speech activity. Moscow: Prosvescheniye.

Levina, E. Y., Akhmetov L. G., Latipova L. N., Mirzagitova A. L., Mirzanagimova F. I., Latipov Z. A., \& Masalimova, A. R. (2015). Diagnostics of Educational Activity Quality on the Basis of Qualitative Methods. Asian Social Science, 11(4), 246-251.

Lopatina, O. V., Borisov, A. M., Leyfa, I. I., Galimzyanova, I. I., Yatsevich, L. P., Demyanenko, M. A., \& Masalimova, A. R. (2015). Role of foreign language teacher shaping students' research skills. Asian Social Science, 11(4), 135.

Lopatina, O. V., Fassakhova, G. R., Akhmetova, L. A., Gatin, R. G., Yarullina, A. S., Nikishina, S. R., \& Khairullina, E. R. (2015). The Technology of Forming the Students' Research Competence in the Process of Learning a Foreign Language. Asian Social Science, 11(3), 152-157.

Lozanov, G. (1979). Suggestopedia in teaching foreign languages. In Intensive methods of teaching foreign languages, Issue 1 (pp. 9-17). Moscow: Maurice Thorez Moscow State Pedagogical Institute of Foreign Languages.

Masalimova, A. R., Ikramova, G. D., Shaidullina, A. R., Gubaidullina, G. T., \& Apraksina, N. D. (2014). Distant in-company foreign language learning involving university student-tutors. American Journal of Applied Sciences, 11,1123-1127. http://dx.doi.org/10.3844/ajassp.2014.1123.1127

Oller, J. W., Oller, S. D., \& Oller, S. N. (2014). Milestones: Normal speech and language development across the life span (2nd ed.). San Diego, CA: Plural Publishing, Inc.

Passov, E. I. (2000). The program concept of communicative foreign language education. Moscow: Prosvescheniye.

Petrusinsky, V. V. (1987). Automated systems for intensive training. Moscow: Vysshaya shkola.

Plesnevich, A. S. (1977). Theoretical Foundations of the accelerated course of the English language teaching by the method of "immersion". In Methods of intensive teaching of foreign languages, Issue 3 (pp. 142-148). Moscow: Maurice Thorez Moscow State Pedagogical Institute of Foreign Languages.

Plyukhina, Z. A. (1991). The English say so. Moscow: Vysshaya shkola.

Rakhmanov, I. V. (1980). Teaching oral speech in a foreign language. Moscow: Vysshaya shkola.

Rivers, W. M. (1968). Teaching Foreign Language Skill. Chicago: The University of Chicago Press.

Sabirova, D. R. (2010). Quality of foreign language education in the system "school-university" in the context of modern educational paradigm of the Republic of Tatarstan. A series of Pedagogical sciences, 92, 254-258.

Sabirova, D. R. (2013). Functioning of the English language in the context of globalization: Changing the historical narrative. Philology and Culture, 1, 256-259.

Shaidullina, A. R., Masalimova, A. R., Vlasova, V. K., Lisitzina, T. V., Korzhanova, A. A., \& Tzekhanovich, O. M. (2014). Education, science and Manufacture Integration Models features in Continuous Professional Education System. Life Science Journal, 11(8s), 478-485.

Shaidullina, A. R., Merzon, E. E., Zakirova, V. G., Mokeyeva, E. V., Karev, B. A., Burdukovskaya, E. A., \& Polevaya, N. M. (2015). The Peculiarities of Perspective Students Selection Mechanism by the Future Employers-Enterprise. Review of European Studies, 7(1), 68-73.

Shakirova, A. A., \& Valeeva, R. A. (2014). Humanization of teaching foreign languages: Foreign experience. Obrazovanie i samorazvitie, 2(40), 72-75.

Shcherba, L. V. (1974). Language system and speech activity. Leningrad: Nauka.

Shrum, J. L., \& Glisan, E. W. (2009). Teacher's Handbook: Contextualized Language Instruction. Heinle.

Sibgatova, K. I., Sabirov, I. T., Sadovaya, V. V., Vlasova, V. K., Leyfa, I. I., Yatsevich, L. P., Fassakhova, G. R., \& Vlasova, V. K. (2015). Pedagogical Potential of the Career Guidance Course "Professional Career Planning" to Form Pupils and Students?Self-Determination in the Integrated System "School-Vocational College". Review of European Studies, 1(7), 80-85. 
Stevick, E. W. (1990). Humanism in Language Teaching: A critical perspective. Oxford: Oxford University Press

Valeev, A. A. (2013). Bilingual Education in the Republic of Tatarstan. The Russian-American education forum: An online journal, 5(1/2). Retrieved from http://www.rus-ameeduforum.com/content/en/?task=art\&article=1000969\&iid=15

Valeeva, R. A., Koroleva, N. E., \& Sakhapova, F. K. (2014). Civic education of the technical university students in foreign language classes. Review of European Studies, 7(1), 176-181. http://dx.doi.org/10.5539/res.v7n1p176

Vygotsky, L. S. (1983). Works (Vol 3). Moscow: Pedagogika.

Zankov, L. V. (1962). On the subject and research methods. Moscow: Publishing House of the Academy of Pedagogical Sciences of the RSFSR.

Zimnyaya, I. A. (1991). Psychology of foreign languages teaching in school. Moscow: Prosvescheniye.

\section{Copyrights}

Copyright for this article is retained by the author(s), with first publication rights granted to the journal. This is an open-access article distributed under the terms and conditions of the Creative Commons Attribution license (http://creativecommons.org/licenses/by/3.0/). 